TERRA. Revista de Desarrollo Local e-ISSN: 2386-9968

Número 6 (2020), 228-253

DOI 10.7203/terra.6.17406

IIDL - Instituto Interuniversitario de Desarrollo Local

\title{
Procesos recientes de segregación e incorporación de municipios en Andalucía. ¿La fusión o la cooperación como solución al minifundismo local?
}

\author{
Luis Copano Ortiz \\ Dr. en Geografía por la Universidad de Sevilla. Junta de Andalucía, Dirección General \\ de Fondos Europeos (Sevilla, España) \\ luis.copano@juntadeandalucia.es \\ https://orcid.org/0000-0002-3438-3447 \\ Jesús Ventura Fernández \\ Prof. Titular Dpto. de Geografía Física y Análisis Geográfico Regional. Universidad de \\ Sevilla (Sevilla, España) \\ jventura@us.es \\ https://orcid.org/0000-0002-8271-1011
}

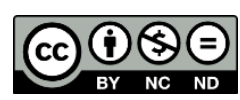

Esta obra se distribuye con la licencia Creative Commons Reconocimiento-NoComercial-SinObraDerivada 4.0 Internacional 


\title{
SECCIÓN ARTÍCULOS
}

\author{
Procesos recientes de segregación e incorporación de municipios en Andalucía. ¿La fusión o la \\ cooperación como solución al minifundismo local?
}

Resumen: El mapa municipal andaluz está compuesto en la actualidad por 785 municipios, aunque esta realidad política, administrativa y territorial ha experimentado un auge importante de los fenómenos segregacionistas durante el período constitucional, siendo especialmente numerosos durante la última década, con la creación de 14 municipios, con base jurídica mayoritaria en la Ley de Autonomía Local de Andalucía (2010). Con la Ley, estatal, de Racionalización y Sostenibilidad de la Administración Local (2013), se han endurecido las condiciones para la segregación, estableciéndose el umbral poblacional mínimo de 5.000 habitantes y su viabilidad financiera. El objetivo de esta investigación es profundizar en la posición actual de la Junta de Andalucía en los procesos de segregación e incorporación de términos municipales, así como en las posibilidades segregacionistas futuras. Para ello se aplicará, a modo de metodología, una revisión de toda la normativa sobre régimen local y de sus repercusiones en el mapa municipal andaluz. Los principales resultados exponen la panorámica actual al respecto. Y como conclusión, se presentarán diversas alternativas: bien la fusión de municipios de escasa entidad poblacional y con problemas financieros, o bien el reforzamiento de figuras de cooperación territorial (mancomunidades, consorcios) o la creación de entidades supramunicipales (comarcas administrativas, áreas metropolitanas).

Palabras clave: Autonomía Local, Mapa municipal, Nuevos ayuntamientos, Segregación, Andalucía.

\section{Recent processes of segregation and incorporation of municipalities in Andalucía. Fusion or cooperation as a solution to local minifundism?}

\begin{abstract}
The Andalusian municipal map is currently composed of 785 municipalities, although this political, administrative and territorial reality has experienced a significant boom in segregationist phenomena during the constitutional period, being especially numerous during the last decade, with the creation of 14 municipalities, with a majority legal basis in the Local Autonomy Law of Andalusia (2010). With the State Law on Rationalization and Sustainability of the Local Administration (2013), the conditions for segregation have been tightened, establishing a minimum population threshold of 5,000 inhabitants and their financial viability. The objective of this research is to deepen the current position of the Junta de Andalucía in the processes of segregation and incorporation of municipality, as well as future segregationist possibilities. For this end, a review of all the regulations on local government and their repercussions on the Andalusian municipal map will be applied as a methodology. The main results set out the current overview in this regard. And as a conclusion, various alternatives will be presented: either the merger of municipalities with small population and financial problems, or the strengthening of territorial cooperation figures (communities of municipalities, consortiums) or the creation of supra-municipal entities (administrative regions, metropolitan areas).
\end{abstract}

Key words: Local autonomy, Municipal map, New councils, Segregation, Andalucía.

Recibido: 19 de mayo de 2020

Devuelto para revisión: 4 de junio de 2020

Aceptado: 30 de junio de 2020

\section{Referencia / Citation:}

Copano, L., y Ventura, J. (2020). Procesos recientes de segregación e incorporación de municipios en Andalucía. ¿La fusión o la cooperación como solución al minifundismo local?. TERRA. Revista de Desarrollo Local, (6), 228-253. DOI 10.7203/terra.6.17406 
IDEAS CLAVE / HIGHLIGHTS / IDEES CLAU

1. Las segregaciones municipales tienen un carácter excepcional según la actual legislación estatal (LRSAL, 2013) y su exigencia de superar los 5.000 habitantes.

2. En Andalucía se han producido 14 segregaciones por debajo de este umbral demográfico, pues su tramitación se inició antes de la entrada en vigor de la LRSAL.

3. A futuro se dificultan las segregaciones en Andalucía, pues solo existe una localidad que cumple ese umbral demográfico.

4. Se considera conveniente mantener los municipios como comunidad política y de participación, y gestionar los servicios públicos en un marco supramunicipal.

5. La estrategia organizativa territorial debe primar la voluntariedad en la fusión de municipios $y$ en el asociacionismo intermunicipal.
1. Municipal segregations are exceptional according to the current state legislation (LRSAL, 2013) and its requirement to exceed 5.000 inhabitants

2. In Andalucía there have been 14 segregations below this demographic threshold, as their processing began before the entry into force of the LRSAL.

3. In the future, segregation in Andalucía will be difficult, as there is only one town that meets this demographic threshold.

4. It is considered appropriate to maintain the municipalities as a political and participatory community and to manage public services in a supramunicipal framework.

5. The territorial organizational strategy must give priority to the voluntary merging of municipalities and inter-municipal associations.
1. Les segregacions municipals tenen un caràcter excepcional segons l'actual legislació estatal (LRSAL, 2013) i la seua exigència de superar els 5.000 habitants.

2. A Andalusia s'han produït 14 segregacions per davall d'aquest llindar demogràfic, perquè la seua tramitació es va iniciar abans de l'entrada en vigor de la LRSAL.

3. A futur es dificulten les segregacions a Andalusia, perquè només existeix una localitat que compleix aqueix llindar demogràfic.

4. Es considera convenient mantindre els municipis com a comunitat política i de participació, i gestionar els serveis públics en un marc supramunicipal.

5. L'estratègia organitzativa territorial ha de prevaldre la voluntarietat en la fusió de municipis i en l'associacionisme intermunicipal. 


\section{OBJETIVOS Y METODOLOGÍA}

El objetivo principal de este estudio es el de dar a conocer la posición de la Junta de Andalucía en los procesos de segregación e incorporación de términos municipales, en especial lo relativo a la segregación municipal referidos a aquellas situaciones más recientes, y que se han visto determinadas ya por la entrada en vigor de la Ley 27/2013 de Racionalización y Sostenibilidad de la Administración Local (LRS AL), que viene a endurecer las condiciones para la creación de nuevos municipios por segregación de otros ya existentes, estableciendo un umbral poblacional mínimo de 5.000 habitantes y la obligatoriedad de que los nuevos ayuntamientos sean financieramente sostenibles.

Además, se realizarán reflexiones sobre las perspectivas futuras para la modificación de municipios, tanto por segregación como mediante fusión entre ellos, realizándose al mismo tiempo un análisis de la estructura administrativa y de poblamiento en Andalucía en relación con el "minifundismo" municipal, así como de las posibilidades existentes de constitución de entes supramunicipales.

Para ello, a nivel metodológico, se realizará una revisión de la normativa sobre régimen local, principalmente la Ley 7/1985 Reguladora de las Bases del Régimen Local (LRBRL) y la Ley 5/2010 de Autonomía Local de Andalucía (LAULA), que derogó la Ley 7/1993 Reguladora de la Demarcación Municipal de Andalucía (LRDMA), así como el Real Decreto 1690/1986 por el que se aprueba el Reglamento de Población y Demarcación de las Entidades Locales, y la antes referida LRSAL (2013). Del mismo modo se prestará especial atención a los fundamentos de Derecho recogidos en los decretos de creación municipal.

Por último, se presentarán diversas alternativas como solución al minifundismo local, que van desde la fusión de municipios de escasa entidad poblacional y con problemas financieros, al reforzamiento de las figuras de cooperación (mancomunidades, consorcios locales) o la creación de entidades supramunicipales (comarcas, áreas metropolitanas).

\section{MARCO TEÓRICO: LA CONFIGURACIÓN DEL MAPA MUNICIPAL ANDALUZ}

El municipio se ha concebido como el cauce de participación de una colectividad de personas para la adopción de decisiones de interés común, lo que ha provocado que, al igual que sucede en la mayoría de los estados de influencia francesa, su número sea muy elevado ${ }^{1}$. Esta excesiva fragmentación determinó que, ya en el siglo XIX, se insistiese en la necesidad de acometer una profunda reforma del mapa municipal, "al considerar que, por debajo de un determinado mínimo poblacional, la gestión de los servicios públicos locales resultaba ineficaz" (Santiago, 2012, p. 169).

Según indican Burgueño y Guerrero (2014), los principales hitos en la trayectoria histórica del mapa local español permiten identificar 5 estadios en época contemporánea: un primer mapa municipal, surgido con la Constitución de 1812, tendente a la descentralización del poder en la Administración Local, que obliga a tener ayuntamiento a aquellos pueblos en los que conviniera, no pudiendo dejar de haberlos en los que

\footnotetext{
${ }^{1}$ En España existen un total de 8.131 municipios, de los que aproximadamente un $65 \%$ no superan los 1.000 habitantes. En Andalucía, estos municipios apenas alcanzan el $28 \%$, por lo que el minifundismo local no es tan acuciante como en el resto del Estado.
} 
superaran los 1.000 habitantes; un segundo mapa municipal en el que se alcanzará el máximo histórico de municipios (alrededor de 11.300), tras la consolidación de la legislación liberal; un tercero, resultado de la aplicación del artículo 70 de la Ley sobre Organización y Atribuciones de los Ayuntamientos de 1845, en el que, siendo fiel reflejo de su tendencia a la centralización administrativa, se obliga a aquellos municipios inferiores a los 30 vecinos a agregarse a los municipios existentes o a unirse entre sí para formar otros nuevos; un cuarto mapa municipal, durante el tardofranquismo, cuando se promovió la fusión de ayuntamientos, alcanzándose en 1980 el mínimo histórico, con $8.020 ; \mathrm{y}$, por último, un quinto mapa municipal que, como consecuencia del fortalecimiento de la identidad y la autonomía municipal, va a suponer un incremento sostenido en el número de municipios, hasta alcanzar los 8.131 en la actualidad.

Por su parte, el mapa municipal andaluz se compone, en estos momentos, de 785 municipios, habiéndose constatado un auge importante del fenómeno segregacionista desde el inicio del período constitucional, en gran parte como reacción a la tendencia aglutinadoramente coercitiva ${ }^{2}$ que se desarrolló con fuerza durante la etapa franquista (Ventura, 1991).

Desde el punto de vista del poblamiento, y dentro de una dinámica que se ha visto transformada sobre todo en la segunda mitad del siglo XX, Andalucía se caracteriza por presentar una notable complejidad, siendo dominantes los asentamientos de carácter concentrado en áreas como las campiñas del Guadalquivir o el corredor intrabético, apareciendo formas de acusada dispersión en las tierras más orientales de las Cordilleras Béticas, y encontrándose toda una gama de situaciones intermedias en los espacios serranos, tierras de regadío o franjas litorales (Florido, 2003).

No obstante, cabe realizar la siguiente esquematización del poblamiento sobre el territorio andaluz: una franja septentrional (Sierra Morena) con carácter concentrado y población escasa; el Bajo Guadalquivir, con población abundante y poblamiento concentrado; la zona oriental, con población escasa y poblamiento disperso; y el litoral mediterráneo, con poblamiento disperso y población elevada. Solo, en una poco definida pero extensa área central, encontramos el típico poblamiento concentrado con hábitat intercalar, esto es, la presencia de pueblos grandes a los que se superpone una fina malla de pequeñas unidades de explotación agraria (cortijo andaluz), si bien muy condicionada por una población en regresión evidente (Ventura y Ayala, 1987).

Como consecuencia de este poblamiento, tendente en general a la concentración, en el conjunto andaluz predominan los términos municipales extensos $(33,5 \%$ de los municipios poseen más de $100 \mathrm{~km}^{2}$ ), siendo destacables las superficies correspondientes a Córdoba $\left(1.255 \mathrm{~km}^{2}\right)$ y Jerez de la Frontera $\left(1.188 \mathrm{~km}^{2}\right)$. En el lado opuesto, y fruto de un poblamiento disperso, localizado, fundamentalmente, en la parte oriental, nos encontramos con términos municipales que no alcanzan ni siquiera los $10 \mathrm{~km}^{2}$, que representan el 5,6\% del total.

\section{TRANSFORMACIONES RECIENTES EN EL MAPA MUNICIPAL ANDALUZ}

Durante el período preautonómico estuvo vigente la legislación sobre régimen local de la etapa franquista: el Decreto de 24 de junio de 1955 por el que se aprueba el texto

\footnotetext{
${ }^{2}$ Durante los años 70 del siglo pasado se produjeron en Andalucía una treintena de modificaciones municipales por fusión entre municipios o incorporación de términos municipales a otros limítrofes.
} 
articulado y refundido de las leyes de bases de Régimen Local, así como aquellos artículos del Decreto de 16 de diciembre de 1950 por el que se aprueba el texto articulado de la Ley de Régimen Local, de 17 de julio de 1945, y el Reglamento de población y demarcación territorial de las Entidades Locales (Decreto de 17 de mayo de 1952).

En esta normativa se establece que, para la creación de nuevos municipios, será necesario que cuenten con población, territorio y riqueza disponible suficientes para sostener los servicios municipales obligatorios, siempre que los que soporten la segregación no sufran un menoscabo para el cumplimiento de las condiciones que se exigen para la segregación. No obstante, se permitía la segregación, sin el cumplimiento de las condiciones mencionadas, cuando existieran motivos permanentes de interés público relacionados con la colonización interior, explotación de minas, instalación de nuevas industrias, conversión de terrenos en regadíos, obras públicas u otros análogos. Además, en el caso de que la segregación fuera solicitada por una Entidad Local Menor ${ }^{3}$ (ELM), no sería requisito indispensable el acuerdo favorable del ayuntamiento del que dependiera, aunque sí su informe del caso.

A pesar de esta posibilidad de creación de nuevos ayuntamientos, con estas disposiciones se potenciaban los procesos de reducción de municipios, tanto por medio de la incorporación a municipios limítrofes (aunque el municipio que se integrara no debía perder su identidad), como mediante la fusión de municipios (por carecer de forma separada de los suficientes recursos económicos para prestar los servicios mínimos obligatorios o cuando existiera continuidad entre los núcleos urbanos por el desarrollo de las edificaciones), enmarcándose en un debate de ámbito europeo sobre la necesidad de optimizar las estructuras del gobierno local. De esta forma, el Real Decreto 3046/1977, por el que se articula parcialmente la Ley 41/1975 de Bases del Estatuto de Régimen Local, establecía un régimen especial para los municipios con población inferior a 5.000 habitantes, para los que se planteaban diversas situaciones por las que sería necesario la agrupación forzosa para la prestación de una serie de servicios.

Asimismo, se promovían fórmulas de cooperación voluntaria entre municipios por medio de la creación de mancomunidades para obras, servicios u otros fines de competencia municipal, y la agrupación forzosa de municipios para la ejecución además de obras públicas subvencionadas por el Estado y la prestación, por delegación, de servicios de competencia estatal; y, posteriormente, por medio de la Ley 41/1975 de Bases del Estatuto de Régimen Local (LBERL), seguía fomentándose la agrupación de municipios mediante la adición de nuevas figuras: entidades municipales metropolitanas, para aquellas aglomeraciones urbanas de elevada densidad demográfica e importante vinculación económica y social; y entidades municipales de ámbito comarcal, para la programación unitaria del desarrollo económico y social o para la organización en común de los servicios municipales.

De esta forma, no es de extrañar que desde el año 1963, en el que Punta Umbría (segregada de Cartaya, Huelva) se constituye como municipio, hasta el año 1981, con la independencia de Cuevas del Campo (de Zújar, Granada), las diversas alteraciones de

\footnotetext{
${ }^{3}$ El concepto de "Entidad Local Menor" es introducido por el Estatuto Municipal de 1924, conocido como Estatuto de Calvo Sotelo, durante la dictadura de Primo de Rivera, que marca un nuevo hito en el régimen de aquellas entidades de ámbito territorial inferior al municipal, englobando a los "anejos, parroquias, lugares, aldeas, caseríos y poblados que, dentro de un municipio, y constituyendo núcleo separado de edificaciones, forman conjunto de personas y bienes, con derechos o intereses peculiares y colectivos diferenciables de los generales del municipio".
} 
términos municipales en Andalucía se debieran bien a fusiones ${ }^{4} \mathrm{o}$ bien a agregaciones de municipios $^{5}$, concentradas sobre todo en Andalucía oriental donde, tradicionalmente, el minifundismo local ha estado más presente, por las razones de poblamiento disperso antes referidas, constatándose solo dos segregaciones más bajo esta normativa: El Ejido (de Dalías, en Almería) y La Mojonera (de Felix, Almería).

A pesar del planteamiento inicial tendente a la concentración de municipios de menos de 500 habitantes y la redacción de un mapa municipal con una división ideal de términos municipales para cada provincia y la tendencia a crear municipios-comarca, al tiempo que se propugnaba una cierta representación en los nuevos ayuntamientos de los núcleos agrupados (Burgueño, 2004), se puso freno a esta corriente debido a la falta de consenso.

\subsection{Ley 7/1985 Reguladora de las Bases de Régimen Local}

Con la nueva configuración territorial del Estado, las autonomías y las entidades locales comienzan a demandar la aprobación de una nueva ley de régimen local adaptada a la Constitución y al concepto de autonomía local, por lo que se aprueba la Ley Reguladora de las Bases de Régimen Local (1985), que indicaba que la creación de municipios solo podía realizarse a partir de la existencia de núcleos de población territorialmente diferenciados, y siempre que los municipios resultantes contasen con suficientes recursos para el cumplimiento de sus competencias y no supusieran una disminución de la calidad de servicios que venían siendo prestados a la población (art. 13.2), mientras que, para la fusión de municipios, se dejaba la posibilidad al Estado para que, sin perjuicio de las competencias de las comunidades autónomas, y atendiendo a criterios geográficos, sociales, económicos y culturales, pudieran establecerse medidas para su fomento, con el fin de mejorar la capacidad de gestión. En cuanto a las entidades locales supramunicipales, se siguen manteniendo las mancomunidades de municipios y, aunque con una revisión en su denominación, las áreas metropolitanas y comarcas, suprimiéndose las agrupaciones forzosas de municipios, así como los procedimientos de creación, supresión y alteración de términos municipales en cada una de ellas (art. 13.1).

Según el Reglamento de Población y Demarcación Territorial de las Entidades Locales (Real Decreto 1690/1986), el inicio de los expedientes de alteración de términos municipales se podrá decretar por el órgano competente de cada comunidad autónoma en esta materia, bien de oficio o a instancia de cualesquiera de los ayuntamientos interesados, de las diputaciones provinciales respectivas, de la Administración del Estado o por medio de otros órganos de la comunidad autónoma que, en razón de sus respectivas competencias, consideren procedente la alteración. Además, la disposición transitoria determinaba que los expedientes de alteración de términos municipales iniciados antes de

\footnotetext{
${ }^{4}$ Se crean 17 municipios por fusión a partir de 43 existentes, lo que supone una reducción de 26 municipios: en la provincia de Granada, Lecrín (a partir de los municipios de Acequias, Chite y Talará, Mondújar, Béznar y Murchas), Nevada (Laroles, Mairena y Picena), Valle del Zalabí (Alcudia de Guadix, Charches y Esfiliana), Los Guájares (Guajar-Alto, Guajar-Faragüit y Guajar-Fondón), Alpujarra de la Sierra (MecinaBombarón y Yegen), Las Gabias (Gabia la Chica y Gabia la Grande), Morelábor (Laborcillas y Moreda), El Valle (Melegís, Restábal y Saleres), La Tahá (Pitres, Ferreirola y Mecina-Fondales), Villamena (Cónchar y Cozvíjar), El Pinar (Pinos del Valle e Ízbor), Vegas del Genil (Ambroz, Belicena y Purchil); en la provincia de Jaén, Cárcheles (Cárchel y Carchelejo), Bédmar y Garcíez (Bédmar y Garcíez), SantiagoPontones (Santiago de la Espada y Pontones) y Villatorres (Torrequebradilla y Villagordo); y en la provincia de Almería, Las Tres Villas (Doña María Ocaña y Escúllar).

${ }^{5}$ En la provincia de Granada desaparecen Jorairátar (agregado a Ugíjar), Cherín (a Ugíjar), Dehesas Viejas (a Iznalloz), Yátor (a Cádiar), Narila (a Cádiar), Caparacena (a Atarfe), Játar (a Arenas del Rey), Fornes (a Arenas del Rey), Alcázar y Fregenite (a Órgiva) y Ventas de Zafarraya (a Alhama de Granada); así como Solera (a Huelma, en la provincia de Jaén) y Peñarrubia (a Campillos, en la de Málaga).
} 
la fecha de entrada en vigor de ese Reglamento debían ajustarse en su tramitación al nuevo procedimiento previsto en el mismo.

Por medio de esta normativa estatal, se constituyeron, como municipios independientes, Cañada Rosal (de La Luisiana, en Sevilla), Zagra (de Loja, Granada), Torremolinos (segregado de Málaga capital), Arroyo del Ojanco (de Beas de Segura, Jaén), BenalupCasas Viejas (de Medina Sidonia, Cádiz) y El Cuervo de Sevilla (de Lebrija, Sevilla), si bien solo estos dos últimos comenzaron su tramitación tras la aprobación de la LRBRL (1985).

Por contra, una serie de núcleos de población, algunos de los cuales habían sido municipios independientes hasta que en la década de los 70 del siglo pasado se fusionaron o agregaron a otros para formar nuevos municipios, también impulsaron sus procesos de segregación, si bien las iniciativas para recuperar su independencia municipal fueron desestimadas, a pesar de contar con el apoyo de sus respectivos ayuntamientos matrices ${ }^{6}$ : en 1988, las localidades jiennenses de Cárchel (Cárcheles), Garcíez (Bédmar y Garcíez) y Játar y Fornes (ambos pertenecientes a Arenas del Rey), y las granadinas de Cónchar (Villamena), Ízbor (El Pinar), Picena (Nevada) y Ventas de Zafarraya (Alhama de Granada); en 1989, Yegen (Alpujarra de la Sierra, Granada); y en 1992, La Guijarrosa (Santaella, Córdoba). Entre los motivos que se alegaron para denegar las segregaciones se encuentran los de carácter económico, ya que no disponían de recursos suficientes para afrontar los gastos correspondientes a su pretendida independencia municipal, así como la posible merma en los servicios que ya se prestaban a los ciudadanos.

\subsection{Ley 7/1993 Reguladora de la Demarcación Municipal de Andalucía}

Sentadas las bases legales del Estado en lo referido a su organización territorial y al Régimen Local, las comunidades autónomas comenzaron a desarrollar instrumentos normativos en la misma materia, siendo la Ley Reguladora de la Demarcación Municipal de Andalucía (1993) la normativa de referencia para el caso andaluz.

Esta Ley expresaba, en su exposición de motivos, la voluntad del legislador autonómico de alterar lo menos posible la realidad territorial andaluza, subrayando la relevancia de la figura de la Entidad Local Autónoma o ELA (antiguas entidades locales menores) como un instrumento adecuado para canalizar las aspiraciones de autogestión que pudieran tener los vecinos de una localidad que no fuese cabecera municipal. Sin embargo, en muchas ocasiones, las ELA consideraron este régimen jurídico como transitorio respecto al que realmente aspiraban a alcanzar, y que no era otro rango que la condición de nuevo municipio por segregación. En cuanto a las fusiones, se evitaron medidas coercitivas que supusieran una pérdida de la autonomía local de los municipios, en lugar de apostar por los supuestos beneficios funcionales que podía suponer la reducción del mapa municipal para una mejor gestión de los servicios públicos.

Este interés normativo por mantener inalterada la organización territorial, tiene su concreción en la apuesta firme por fórmulas asociativas que permitan racionalizar esfuerzos y recursos para una mejor ejecución de sus competencias, siempre que no debiliten o vacíen de contenido la autonomía o la gestión propias de cada municipio, por lo que se promueve la creación de mancomunidades y consorcios para la prestación de

${ }^{6}$ El Ayuntamiento de Santaella (Córdoba) mostró no obstante su oposición a la segregación de La Guijarrosa mediante acuerdo plenario de 26 de junio de 1990 al considerar que, de forma inequívoca, con tal medida se perjudicaría no solo a la parte segregada, sino al resto del municipio resultante, además de argumentar que en ningún período histórico este núcleo había alcanzado la categoría de municipio. 
servicios municipales, si bien no se recoge la regulación de las comarcas administrativas y se deja casi sin contenido jurídico a las áreas metropolitanas, cuya regulación deberá establecerse en una ley especial de creación de cada una de ellas (hasta el momento no se ha constituido ninguna en Andalucía).

Hay que destacar también que esta Ley permitirá que los expedientes de creación y supresión de municipios, o de alteración de sus términos, pudieran iniciarse también por medio de una Comisión Promotora que acreditara la representación de la mayoría de los vecinos en el núcleo de población que aspirase a la segregación (art. 12.2).

En su artículo 8, se establecían las condiciones necesarias para la creación de un nuevo municipio por segregación, cuando concurrieran, de forma simultánea, las siguientes circunstancias: un volumen poblacional no inferior a 4.000 habitantes, la existencia de una franja de suelo no urbanizable de una anchura mínima de 7.500 metros entre el núcleo matriz y el que pretendiera la segregación, y que el nuevo municipio dispusiese de territorio y recursos suficientes para el cumplimiento de las competencias municipales que permitan mantener o incrementar la calidad media de los servicios que ya disfrutaban sus vecinos.

En cuanto a las segregaciones sobre la base de territorios constituidos por ELA, y que hayan tenido esta condición por un período mínimo de cinco años con anterioridad al inicio del expediente de segregación, se entiende que ya existe una identidad propia y diferenciada, rebajándose los requisitos cuantitativos relativos a la población (si bien no inferior a 2.500 habitantes) y a la separación entre núcleos (en este caso de solo $5 \mathrm{~km}$ ).

No obstante, la única ELA que logró acceder a la condición de municipio realizando todo el procedimiento durante el período de vigencia de esta Ley fue Villanueva de la Concepción (de Antequera, en Málaga), acogiéndose a la reducción de las exigencias recogidas en el artículo 8.4, ya que los municipios de Isla Mayor ${ }^{7}$ (de La Puebla del Río, Sevilla) y San José del Valle (de Jerez de la Frontera, Cádiz) comenzaron su tramitación con anterioridad a la vigencia de esta disposición. En cuanto a Balanegra (Berja, Almería) y San Martín del Tesorillo (Jimena de la Frontera, Cádiz), iniciaron su procedimiento durante la vigencia de esta Ley, si bien su constitución como municipios se produjo cuando ya se había derogado la misma.

En el caso de Balanegra, no se admitió su solicitud de segregación (Decreto 82/2007) al considerarse que no se podía acoger al artículo 8.4, ya que se partía de la consideración de que las entidades locales menores constituidas con anterioridad a la entrada en vigor de la LRDMA debían tramitar un procedimiento de adaptación al régimen jurídico específico establecido en dicha Ley para las ELA. Sin embargo, el Tribunal Superior de Justicia de Andalucía (TSJA), en sentencias de 14 de abril de 2008, 3 de mayo 2010 y 2 de diciembre de 2013 (ésta ya firme), mantiene que "las ELA no son otras que las EATIM" (Entidad de Ámbito Territorial Inferior al Municipal como nueva denominación de las antiguas entidades locales menores) y que "el proceso de adaptación a que se refería la LRDMA solo puede referirse a cuestiones formales de cambio de denominación, inscripción correspondiente, etc." (Copano y Ventura, 2013, p. 159), por lo que por medio del Decreto 144/2015 se aprobó finalmente la creación de dicho municipio.

Por su parte, San Martín del Tesorillo no se constituirá en municipio hasta el año 2018, a pesar de iniciar su procedimiento de segregación en 2008, debido, principalmente, a que

\footnotetext{
${ }^{7}$ La modificación toponímica se produjo mediante el Decreto 402/2000, de 5 de octubre, por el que se aprueba el cambio de denominación del municipio de Villafranco del Guadalquivir por el de Isla Mayor, de la provincia de Sevilla.
} 
en la documentación aportada no se ofrecían garantías del nivel de endeudamiento y del objetivo de estabilidad, por lo que se examinaron a fondo sus cuentas para verificar que se daba cumplimiento a los apartados 2 y 3 del artículo 8 de la LRDMA.

Las iniciativas de segregación de La Barca de la Florida (Jerez de la Frontera, Cádiz) y Mazagón (entre los municipios de Moguer y Palos de la Frontera, Huelva), en 2007 y 2008 respectivamente, así como la de San Pedro de Alcántara (Marbella, Málaga), en 2011, contaban con la oposición de sus respectivos ayuntamientos; no así la de CarchunaCalahonda (Motril, Granada), de 2014, que finalmente logró un acuerdo plenario favorable.

En estos casos, las motivaciones desestimatorias de carácter territorial y funcional adquieren relevancia respecto a las económicas: en el primer caso (La Barca de la Florida) se indica que no se constata la existencia de un entramado de relaciones sociales, culturales, económicas y de servicios entre los núcleos que pretendían la segregación, en gran medida por la importante distancia existente entre ellos; y en el caso de Mazagón se afirmaba que "no es una propuesta coherente desde el punto de vista territorial", ya que no se ajustaba a las determinaciones de los planes de Ordenación del Territorio aprobados (tanto regional como subregional), y que el ámbito territorial pretendido era excesivo en función de su peso poblacional. Para los casos de San Pedro de Alcántara y CarchunaCalahonda se indicó que no existían franjas de terreno de anchura suficiente clasificadas como suelo no urbanizable, respecto al núcleo cabecera.

\subsection{Ley 5/2010 de Autonomía Local de Andalucía}

Esta Ley viene a clarificar toda la materia relativa al régimen local a nivel andaluz y, en cuanto a la creación de municipios, introducirá novedades, ya que en su artículo 93.2, deja patente su carácter excepcional, necesitando "la conformidad expresa, acordada por mayoría absoluta, del pleno del ayuntamiento del municipio que sufre la segregación"; $y$, en cuanto a la iniciativa del procedimiento también incorpora una importante novedad, ya que no permite que lo inicie una Comisión Promotora que acredite la representación de la mayoría de los vecinos, debiendo provenir su incoación del Ayuntamiento, la Diputación o la Consejería competente sobre régimen local (art. 95.1).

Se establece además la obligatoriedad de que concurran, al menos, las siguientes circunstancias: existencia de motivos permanentes de interés público relacionados con la planificación territorial de Andalucía; identidad propia sobre la base de razones históricas, sociales, económicas, laborales, geográficas y urbanísticas; existencia de una notable dificultad de acceso al núcleo cabecera; disposición de recursos suficientes (capacidad financiera y riqueza imponible del posible nuevo término municipal) para el cumplimiento de las competencias que venía ejerciendo el ayuntamiento del que se segrega; que pueda garantizar la prestación de los servicios públicos con el mismo nivel de calidad que el actual; y que el municipio originario no se vea afectado de forma negativa en la cantidad y calidad de prestación de los servicios de su competencia.

Por tanto, se eliminan los requisitos cuantitativos en cuanto al volumen poblacional del núcleo que pretenda segregarse, así como la distancia mínima de suelo no urbanizable de dicho núcleo respecto al que ostente la capitalidad municipal. No obstante, el principal obstáculo al que deben enfrentarse los procesos de segregación es la exigencia de la conformidad de la mayoría absoluta del pleno del ayuntamiento que soporta la misma (Copano, 2018, p. 93). 
Ahora bien, resulta sorprendente, a pesar de las presumibles dificultades para iniciar el procedimiento de segregación; de la entrada en vigor de la LRSAL el 1 de enero de 2014, con la fijación de un umbral mínimo poblacional (5.000 hab.); y del pronunciamiento desfavorable del Consejo Consultivo de Andalucía $^{8}$ para los municipios que se segregaron en el año 2018, que bajo esta normativa hayan sido hasta 12 los nuevos ayuntamientos que se han conformado: Valderrubio (segregado de Pinos Puente, en Granada), Montecorto (de Ronda, en Málaga), Dehesas Viejas (de Iznalloz, Granada), Serrato (de Ronda, Málaga), Játar (de Arenas del Rey, Granada), Domingo Pérez de Granada (de Iznalloz, Granada), Fuente Carreteros (de Fuente Palmera, Córdoba), Fornes (de Arenas del Rey, Granada), La Guijarrosa (de Santaella, Córdoba), El Palmar de Troya (de Utrera, Sevilla), Torrenueva Costa (de Motril, Granada) y La Zarza-Perrunal (de Calañas, Huelva); así como Tharsis, si bien, en este caso, la Asociación por Alosno (Huelva) interpuso un recurso contencioso-administrativo contra el Decreto 182/2018 de creación del municipio, señalándose en auto del TSJA de 25 de febrero de 2019, la suspensión cautelar del referido Decreto.

Respecto a la agrupación de municipios, esta normativa sigue sin regular las comarcas, que quedan recogidas en el artículo 97 de la Ley Orgánica 2/2007, de 19 de marzo, de Reforma del Estatuto de Autonomía para Andalucía, ni las áreas metropolitanas (en este caso, en el artículo 94), a las que se considera en ambos casos agrupaciones de municipios frente a las asociaciones de los mismos (mancomunidades, consorcios locales). Ahora bien, las comarcas, limitadas a municipios contiguos entre sí con características geográficas, económicas, sociales e históricas afines, ya no tienen que ajustarse a límites uniprovinciales, como determinaba el artículo 5 del anterior Estatuto de Autonomía (1981).

\subsection{Ley 27/2013 de Racionalización y Sostenibilidad de la Administración Local}

Por medio del artículo 1 de esta Ley se va a modificar gran parte del articulado de la LRBRL (1985), al quedar redactado su artículo 13.2 como sigue: "la creación de nuevos municipios solo podrá realizarse sobre la base de núcleos de población territorialmente diferenciados, de al menos 5.000 habitantes y siempre que los municipios resultantes sean financieramente sostenibles, cuenten con recursos suficientes para el cumplimiento de las competencias municipales y no suponga disminución en la calidad de los servicios que venían siendo prestados".

Este nuevo requisito introducido por esta normativa ha sido de gran relevancia para Andalucía, por hallarse en tramitación una serie de iniciativas segregacionistas que no alcanzaban este umbral mínimo poblacional, por lo que se formuló consulta al Ministerio de Hacienda y Administraciones Públicas con objeto de que tal organismo emitiese informe acerca de la procedencia o no de aplicar tal exigencia a los procedimientos antes referidos, concluyéndose, finalmente, que los iniciados con anterioridad a la entrada en vigor de la LRSAL el 1 de enero de 2014 deben resolverse de acuerdo con la normativa vigente en el momento de su incoación. De esta forma, ninguno de los municipios que

\footnotetext{
${ }^{8}$ Se han emitido 8 dictámenes desfavorables: 299/2015 (Fuente Carreteros), 426/2015 (La Guijarrosa), 754/2015 (San Martín del Tesorillo), 25/2018 (Tharsis), 477/2018 (Fornes), 478/2018 (El Palmar de Troya), 479/2018 (Torrenueva Costa) y 533/2018 (La Zarza-Perrunal); y 7 dictámenes favorables 816/2013 (Valderrubio), 609/2014 (Montecorto), 637/2014 (Dehesas Viejas), 738/2014 (Serrato), 25/2015 (Játar), 126/2015 (Domingo Pérez de Granada) y 250/2015 (Balanegra). Cabe indicar que, según el artículo 4 de la Ley 4/2005 del Consejo Consultivo de Andalucía, los dictámenes no serán vinculantes con carácter general, salvo en los casos en que así se establezca en las leyes correspondientes.
} 
alcanzaron su independencia con posterioridad a la entrada en vigor de la LRSAL tuvieron que acogerse al requisito del mínimo poblacional de 5.000 habitantes.

Hay que señalar también que el Tribunal Constitucional ha rechazado la pretendida inconstitucionalidad de este umbral demográfico que plantearon diversas comunidades autónomas, afirmándose, por parte de Carbonell (2018), que:

"la exigencia de que se creen nuevos municipios solo cuando resulten financieramente sostenibles (...) entra dentro, sin lugar a dudas, de la competencia estatal para diseñar el modelo municipal español; exactamente igual la fijación de mínimos poblacionales: el Estado puede desarrollar un modelo municipal al amparo del artículo 149.1.18 de la Constitución basado en mayores exigencias de población y territorio, si lo considera necesario para garantizar la viabilidad del ejercicio de las competencias que se atribuyen a los municipios y con ello su autonomía" (p. 9).

\section{RESULTADOS: SITUACIÓN ACTUAL Y PERSPECTIVAS DEL MAPA MUNICIPAL ANDALUZ}

Como resultado de todas estas transformaciones, el número de municipios se ha incrementado en más de una veintena: 26 segregaciones frente a solo 2 incorporaciones a términos municipales limítrofes (Figura 1 y Tabla 1), siendo en especial numerosas las independencias municipales durante la última década, con la creación de 14 nuevos ayuntamientos, en su mayor parte con base jurídica en la LAULA (2010), todo ello a pesar del inicialmente restrictivo requisito de obtención de la independencia municipal supeditada a su ratificación por parte del pleno del ayuntamiento matriz, y del condicionante de un umbral mínimo de 5.000 hab. establecido por la LRSAL de 2013, si bien este, finalmente, no afectó a los expedientes ya iniciados.

Tabla 1. Relación de segregaciones e incorporaciones de municipios en Andalucía en el período democrático

\begin{tabular}{|l|c|c|c|c|}
\hline \multicolumn{1}{|c|}{ Municipio } & Provincia & $\begin{array}{c}\text { Tipo } \\
\text { modificación }\end{array}$ & Decreto & Normativa \\
\hline Cuevas del Campo & Granada & Segregación & Real Decreto 2916/1980 & Ley 1945 \\
\hline El Ejido & Almería & Segregación & Real Decreto 2251/1982 & Ley 1945 \\
\hline La Mojonera & Almería & Segregación & Decreto 97/1984 & Ley 1945 \\
\hline Benínar & Almería & Incorporación & Decreto 203/1984 & Ley 1945 \\
\hline Cañada Rosal & Sevilla & Segregación & Decreto 224/1986 & LRBRL \\
\hline Zagra & Granada & Segregación & Decreto 114/1987 & LRBRL \\
\hline Torremolinos & Málaga & Segregación & Decreto 283/1988 & LRBRL \\
\hline Benalup-Casas Viejas & Cádiz & Segregación & Decreto 63/1991 & LRBRL \\
\hline El Cuervo de Sevilla & Sevilla & Segregación & Decreto 179/1992 & LRBRL \\
\hline Isla Mayor & Sevilla & Segregación & Decreto 41/1994 & LRDMA \\
\hline Arroyo del Ojanco & Jaén & Segregación & Decreto 469/1994 & LRBRL \\
\hline San José del Valle & Cádiz & Segregación & Decreto 82/1995 & LRDMA \\
\hline Darrícal & Almería & Incorporación & Decreto 123/1997 & LRDMA \\
\hline Villanueva de la Concepción & Málaga & Segregación & Decreto 63/2009 & LRDMA \\
\hline Valderrubio & Granada & Segregación & Decreto 237/2013 & LAULA \\
\hline
\end{tabular}




\begin{tabular}{|l|c|c|c|c|}
\hline \multicolumn{1}{|c|}{ Municipio } & Provincia & $\begin{array}{c}\text { Tipo } \\
\text { modificación }\end{array}$ & Decreto & Normativa \\
\hline Montecorto & Málaga & Segregación & Decreto 135/2014 & LAULA \\
\hline Dehesas Viejas & Granada & Segregación & Decreto 140/2014 & LAULA \\
\hline Serrato & Málaga & Segregación & Decreto 167/2014 & LAULA \\
\hline Játar & Granada & Segregación & Decreto 62/2015 & LAULA \\
\hline Domingo Pérez de Granada & Granada & Segregación & Decreto 105/2015 & LAULA \\
\hline Balanegra & Almería & Segregación & Decreto 144/2015 & LRDMA \\
\hline Fuente Carreteros & Córdoba & Segregación & Decreto 178/2018 & LAULA \\
\hline Fornes & Granada & Segregación & Decreto 179/2018 & LAULA \\
\hline La Guijarrosa & Córdoba & Segregación & Decreto 180/2018 & LAULA \\
\hline San Martín del Tesorillo & Cádiz & Segregación & Decreto 181/2018 & LRDMA \\
\hline El Palmar de Troya & Sevilla & Segregación & Decreto 183/2018 & LAULA \\
\hline Torrenueva Costa & Granada & Segregación & Decreto 184/2018 & LAULA \\
\hline La Zarza-Perrunal & Huelva & Segregación & Decreto 185/2018 & LAULA \\
\hline
\end{tabular}

Fuente: elaboración propia a partir de decretos de constitución e incorporación de municipios y Ministerio de Administraciones Públicas (2018).

Figura 1. Mapa de segregaciones e incorporaciones de municipios en Andalucía en el período democrático

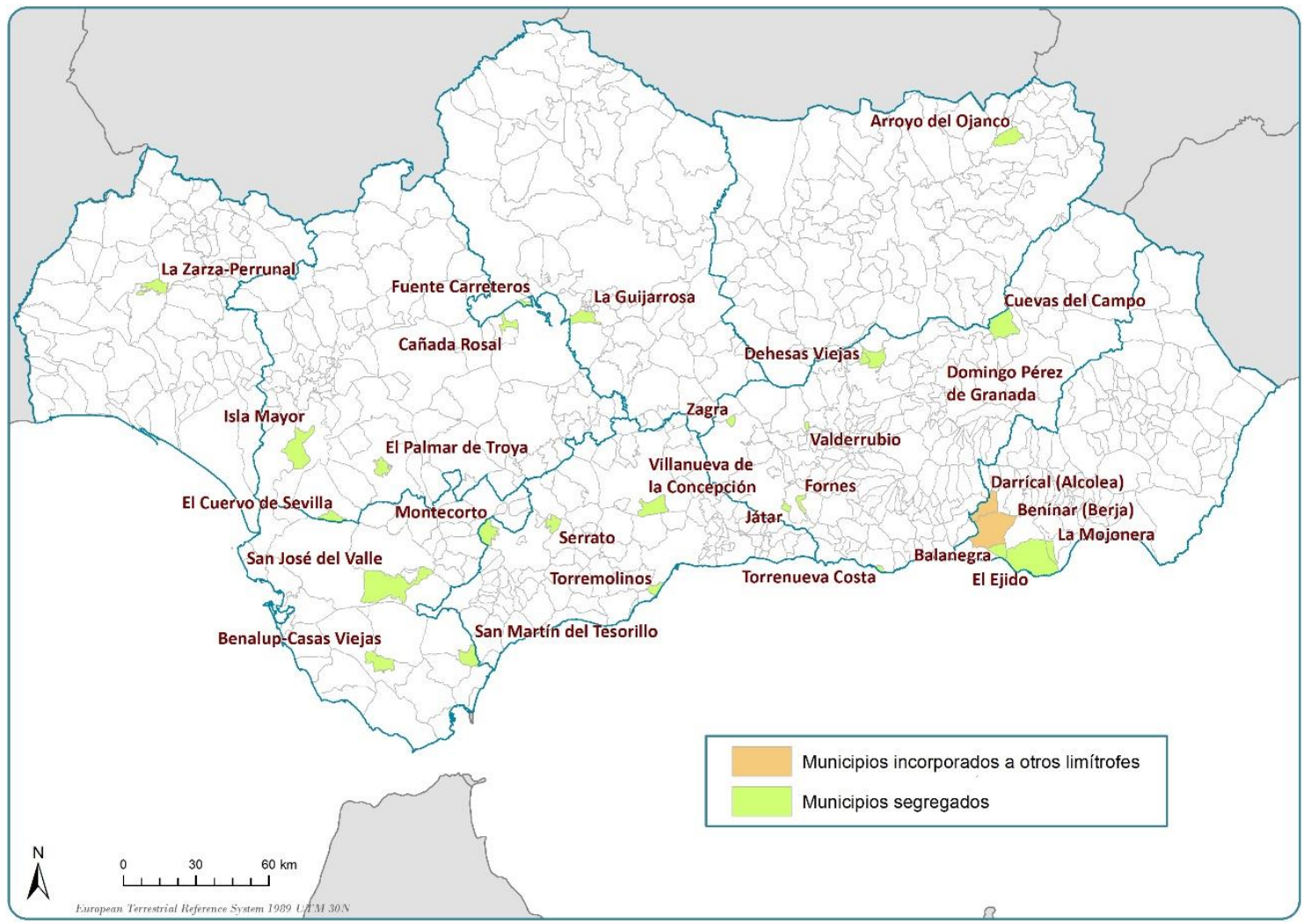

Fuente: elaboración propia a partir de decretos de constitución e incorporación de municipios (2018).

Para aproximarnos al posicionamiento actual de la Junta de Andalucía en relación a las segregaciones municipales nos centraremos en las iniciativas de las ELA de La Barca de la Florida (4.075 hab. según el Nomenclátor de 2017) y Torrecera (1.301 vecinos según la misma fuente), ambas en Jerez de la Frontera. Así, cuando en la Dirección General de 
Administración Local se tuvo constancia de que el pleno del Ayuntamiento de Jerez, de 27 de septiembre de 2013, acordó tomar conocimiento de las aspiraciones segregacionistas de ambas entidades, facultando a las mismas a que elaborasen la documentación preceptiva al amparo del artículo 95.1 c) de la LAULA, que hace referencia a la incoación del procedimiento por parte de la Consejería competente sobre régimen local, desde la Junta de Andalucía se instó a que se realizara sin embargo por medio del artículo 95.1 a), es decir, mediante acuerdo plenario. Finalmente este resolvió no acceder a la petición fundamentándolo en lo siguiente: aplicación del criterio rigorista que se ha empleado desde la aprobación de la LRDMA (no se ha incoado ningún procedimiento de segregación de oficio por parte de la Comunidad Autónoma andaluza ${ }^{9}$ ); carácter de excepcionalidad que marca la LAULA en su artículo 93.2 para las segregaciones municipales; falta de voluntad del Ayuntamiento de Jerez; y una cifra poblacional que no alcanzaba los 5.000 habitantes.

Figura 2. Mapa de Entidades Locales Autónomas en Andalucía

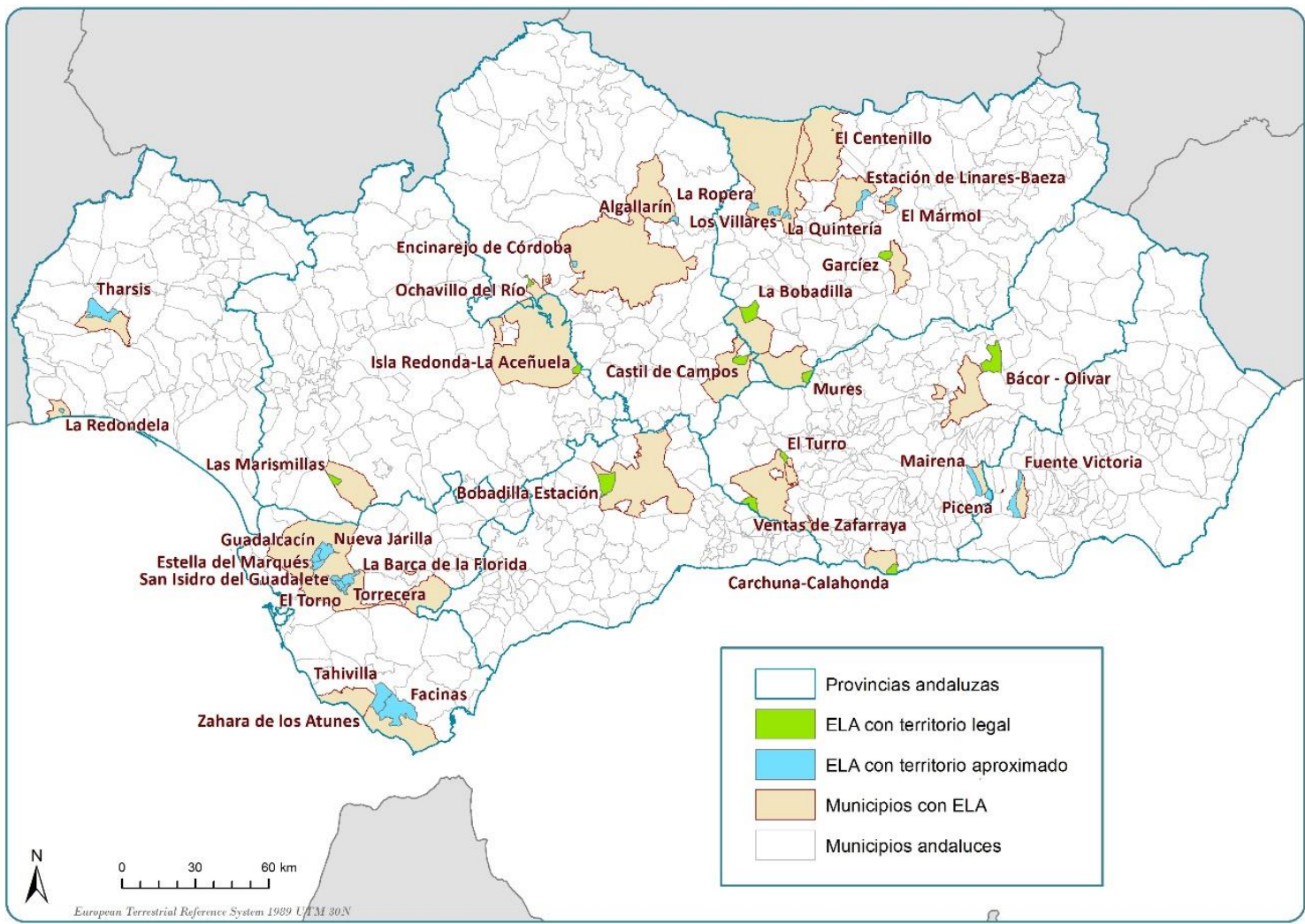

Fuente: elaboración propia a partir de Datos Espaciales de Referencia de Andalucía (2018).

Sin embargo, este carácter rigorista, para los casos jerezanos, y excepcional, no se ha constatado como una barrera infranqueable que haya impedido el culminar favorablemente iniciativas de segregación, y de hecho se han publicado 14 decretos de segregación de nuevos municipios, 7 de ellos en octubre de 2018, con volúmenes poblacionales claramente reducidos en estos últimos, y que oscilan entre los 553

\footnotetext{
${ }^{9}$ La incoación de oficio de este procedimiento supondría una valoración global para todo el mapa municipal andaluz; y además existía un precedente, la ELA de Torrenueva, para la cual no se aceptó, mediante Orden de 20 de diciembre de 2011, que fuera la Consejería la que iniciara de oficio el procedimiento de segregación con respecto al término de Motril, en Granada.
} 
habitantes de Fornes (de Arenas del Rey, en Granada) a los 2.662 de San Martín del Tesorillo (de Jimena de la Frontera, Cádiz), a pesar de distintos dictámenes desfavorables del Consejo Consultivo de Andalucía.

Ahora bien, como ya se ha indicado, la normativa estatal más reciente (2013) es la responsable última de limitar las opciones futuras para la segregación municipal, estableciendo el mencionado umbral poblacional mínimo de 5.000 habitantes, lo que implicaría que de los más de 13.000 asentamientos existentes en Andalucía (contabilizando tanto núcleos como diseminados a nivel toponímico) ${ }^{10}$, solo 34 de ellos cumplirían con el mencionado requisito demográfico. Además, habría que tener en cuenta que ninguno de estos asentamientos se ha constituido en ELA $^{11}$, y que la mayor parte de los núcleos secundarios son realmente urbanizaciones costeras muy próximas a su cabecera municipal o al núcleo principal de otro municipio, careciendo de identidad propia, por lo que, en la práctica, se pone freno a las segregaciones, a pesar de que en ciertas poblaciones sigue existiendo aún un fuerte sentimiento de identidad diferenciada ${ }^{12}$.

En cuanto a las ELA existentes en Andalucía (Figura 2), en la actualidad 35, solo Guadalcacín, situada en el término municipal de Jerez de la Frontera e integrada dentro de su suelo urbano, superaría ese límite poblacional si contamos a la población de su diseminado, pues alcanza los 5.226 habitantes según datos del INE para 2018.

Si analizamos las cifras poblacionales de los actuales 785 municipios andaluces (Tabla 2), es posible apreciar que la exigencia de un mínimo de 5.000 habitantes para la creación de un nuevo municipio puede resultar un requisito riguroso, ya que existen $528(67,3 \%)$ que no alcanzan este límite, siendo casi la mitad los que no superan los 2.500 habitantes.

Tabla 2. Distribución en rangos poblacionales de los municipios andaluces

\begin{tabular}{|l|l|l|l|l|}
\hline Rango poblacional & Número & Porcentaje & Número acumulado & Porcentaje acumulado \\
\hline Menos de 250 hab. & 31 & $3,9 \%$ & 31 & $3,9 \%$ \\
\hline Entre 250 y 499 hab. & 80 & $10,2 \%$ & 111 & $14,1 \%$ \\
\hline Entre 500 y 999 hab. & 108 & $13,8 \%$ & 219 & $27,9 \%$ \\
\hline Entre 1.000 y 2.499 hab. & 159 & $20,3 \%$ & 378 & $48,2 \%$ \\
\hline Entre 2.500 y 3.999 hab. & 112 & $14,3 \%$ & 490 & $62,4 \%$ \\
\hline Entre 4.000 y 4.999 hab. & 38 & $4,8 \%$ & 528 & $67,3 \%$ \\
\hline Entre 5.000 y 9.999 hab. & 104 & $13,2 \%$ & 632 & $80,5 \%$ \\
\hline Entre 10.000 y 24.999 hab. & 96 & $12,2 \%$ & 728 & $92,7 \%$ \\
\hline Entre 25.000 y 49.999 hab. & 28 & $3,6 \%$ & 756 & $96,3 \%$ \\
\hline A partir de 50.000 hab. & 29 & $3,7 \%$ & 785 & $100 \%$ \\
\hline
\end{tabular}

Fuente: elaboración propia a partir de datos del Instituto de Estadística y Cartografía de Andalucía (2019).

\footnotetext{
${ }^{10} \mathrm{Si}$ se consideran aquí todas las entidades poblacionales recogidas en el Nomenclátor del INE (2019), existirían 785 cabeceras municipales, 1.973 núcleos secundarios de población y 2.364 diseminados.

${ }^{11}$ Cabe recordar que bajo normativa andaluza ninguna localidad que previamente no se hubiera constituido como entidad local menor ha alcanzado la independencia municipal.

12 Cabe recordar aquí las aspiraciones históricas de núcleos como Aguadulce (Roquetas del Mar, en Almería), La Herradura (Almuñécar, Granada), La Redondela (Isla Cristina, Huelva), Torre del Mar (VélezMálaga, en la provincia malagueña)...; que, en algunos casos, como el de Mazagón, se traduce en un respaldo del 12,3\% de los votos en las elecciones municipales de 2019 al ayuntamiento de Moguer (Huelva) para la agrupación AVEMA, favorable a la independencia de esta localidad.
} 
En cuanto a las fusiones, a pesar de que la LRSAL ha puesto énfasis especial en las mismas, estableciendo algunas medidas de fomento en el ámbito económico y tributario, y que se supone deben operar como incentivos (Calonge, 2015), no parece que la nueva regulación de las fusiones voluntarias de municipios vaya a ser seguida por muchos de ellos $^{13}$, ni siquiera en aquellos casos que están inmersos en procesos de saneamiento económico. Además, no se da opción para que uno de los municipios fusionados mantenga una posición de identidad administrativa diferenciada, puesto que no pueden constituirse como EATIM, sino solo como una forma de organización desconcentrada, y no descentralizada como son las EATIMES, a las que podemos considerar como entidades locales residuales, al no permitir la actual legislación la conformación de nuevas de ellas.

Por otro lado, el nuevo artículo 116 bis de la LRBRL ha sufrido muy variadas y justificadas críticas por su planteamiento, ya que propugna un caso de fusión de carácter forzoso o sancionador (Palomar, 2015), que supone la formulación de un plan económicofinanciero que incluirá, entre otras cuestiones, una propuesta de fusión con un municipio colindante, dentro de la misma provincia. No resulta previsible que desde la Junta de Andalucía se vaya a hacer uso de esta posibilidad, ya que las referidas fusiones forzosas son una medida más que discutible en términos constitucionales y, aunque son muchas las propuestas que desde el ámbito político ${ }^{14}$ se plantean para reducir el número de municipios mediante la agrupación de los mismos y mejorar así la eficiencia en la gestión administrativa y en la prestación de servicios municipales, sería necesaria una verdadera voluntad política y un consenso político, social y sindical, pues implicaría reorganizar recursos humanos, estructuras políticas, empleos y sentimientos (Trillas, 2010).

Además, desde que la Junta tiene transferidas competencias en materia de régimen local, solo se han producido dos casos: la incorporación de los municipios almerienses de Benínar (1984) y Darrícal (1997), limítrofes con los de Berja y Alcolea respectivamente, como consecuencia de la construcción del embalse de Benínar, causadas, por tanto, por un motivo sobrevenido. Por todo lo argumentado no se espera que, en Andalucía, se produzca una reducción significativa de municipios.

\section{DISCUSIÓN SOBRE SOLUCIONES AL MINIFUNDISMO LOCAL: ¿LA FUSIÓN O LA COOPERACIÓN ENTRE MUNICIPIOS?}

Se hace necesario superar los posicionamientos enfrentados entre los que apuestan por una reducción significativa en el número de entidades territoriales primarias (Rodríguez, 2005), siguiendo la línea marcada por países del Sur de Europa como Portugal, que redujo en 2012 el $35 \%$ de las freguesías existentes, o Grecia, que eliminó en 2010 los municipios que no alcanzaban el umbral poblacional de los 10.000 habitantes; y entre los que se posicionan en el fortalecimiento de la cooperación municipal o creación de figuras supramunicipales (Burgueño, 2004; Llucià, 2011).

Cuando se debate sobre la necesidad de reducir el mapa municipal español, por medio de la supresión de aquellos municipios que no alcanzan un determinado umbral poblacional,

\footnotetext{
${ }^{13}$ Galicia es la única comunidad autónoma en la que se han producido fusiones de municipios: en 2013 Oza-Cesuras (A Coruña) y, en 2016, Cerdedo-Cotobade (Pontevedra), mediante el impulso económico de la Xunta de Galicia.

${ }^{14}$ Por ejemplo, las denominadas fusiones frías propuestas por la formación política Ciudadanos (Cs) para los actuales ayuntamientos con menos de 5.000 hab. (Geografía Infinita, 2015).
} 
se debe tener en cuenta que la problemática del minifundismo local no tiene la misma afección territorial, por lo que las soluciones organizativo-territoriales tampoco deben ser homogéneas; así, utilizando un umbral poblacional de 250 habitantes, las comunidades autónomas con mayor porcentaje de municipios dentro de este rango son Castilla y León (61,9 \% de sus municipios), La Rioja (61,5 \%), Aragón (57,6 \%), Castilla-La Mancha $(44,5 \%)$, Navarra $(40,4 \%)$ y Cataluña $(19,3 \%)$, para un total nacional de 2.839 municipios (16\%). En el lado opuesto destacan la ausencia de municipios menores de 500 habitantes en Murcia y Canarias, la existencia de un único municipio menor de 250 habitantes en Galicia, y solo dos en Principado de Asturias e Illes Balears.

La solución al minifundismo local podría estar, según indica Arenilla (2012), en crear un doble nivel local: se mantendrían los municipios como comunidad política y de participación ciudadana que permitiese conservar la identidad local del pueblo pequeño (excepto en el caso de que no alcanzasen un umbral mínimo de población), aunque la gestión y la prestación de servicios se realizasen en el marco de un espacio territorial supramunicipal, ya fuese por medio de la Diputación Provincial, Cabildo o Consejo Insular, o a través de otras figuras de cooperación territorial como mancomunidades, comarcas administrativas o, en su caso, áreas metropolitanas.

Otras alternativas, no necesariamente innovadoras, puesto que se trata de planteamientos lejanos en el tiempo (Jordana, 1967) que suponen conjugar las opciones comarcalizadora e intermunicipalista, proponían la conversión de los pequeños municipios a una categoría que podría recibir el nombre de "concejo", con mayores competencias que las actuales EATIMES, pero siendo auténticas entidades primarias (similares a la freguesía portuguesa), y reservar el nombre de "municipio" para la entidad compuesta formada por la agrupación de una pluralidad de concejos entre sí o con una población de más importancia, presentando mayores dimensiones y grado de autonomía financiera y política.

Parece claro que las disparidades territoriales aconsejan "descartar políticas generalistas a la hora de legislar sobre el fomento de la eficiencia de los municipios" (Llorente, 2014, p. 373), por lo que la imposición de un simple umbral poblacional o utilizar argumentos meramente economicistas para optar por la fusión de municipios no parecen criterios viables. Según Burgueño (2004):

\begin{abstract}
"existe un posicionamiento social bastante unánime en contra de una reforma radical y traumática del mapa municipal (...). En cambio, una racionalización moderada podría encontrar un apoyo suficiente que la hiciera viable, ya que todos los expertos coinciden en señalar la existencia de casos extremos que exigen de la intervención gubernamental" (p. 29).
\end{abstract}

Las soluciones al minifundismo local deben ser específicas para cada comunidad autónoma; de esta forma, Aragón y Cataluña han aprobado la creación de comarcas, realizando una delimitación de todo su ámbito regional: el modelo aragonés, con 33 delimitaciones comarcales, contó desde sus inicios con un amplio consenso político sustentado en tres elementos: "la capacidad de gestión administrativa por la transferencia de competencias que pertenecían al Gobierno de Aragón, la capacidad de gestión política basada en el autogobierno y la capacidad de gestión económico-social para el desarrollo económico de su territorio" (Infante, 2010, p. 59), lo que conlleva a la supresión de las mancomunidades de municipios que tengan fines similares a las competencias 
comarcales, incorporando sus funciones a las comarcas; por su parte, las 41 comarcas catalanas no tienen un "núcleo de competencias estatutariamente garantizado" (Membrado, 2016, p. 366), por lo que todas son compartidas con otras instituciones, como las mancomunidades o las diputaciones provinciales, y su capacidad de acción dependerá de posibles pactos entre ellos.

Como reacción a la delimitación comarcal administrativa realizada por la Generalitat de Catalunya en 1936 (origen de la actual), se realizaron otras propuestas que pretendían acabar con este nivel competencial (Casassas y Clusa, 1981), por considerar que estaba basado en una organización municipal que procedía de otro contexto político y social. En su análisis territorial y funcional entre los diferentes municipios propusieron el establecimiento de 127 unidades de gobierno o municipalías, "con unos criterios bien razonables, aunque muy difíciles de llevar a la práctica, debido a los intereses municipales con la conocida mezcla de elementos históricos, políticos, económicos, populares e incluso religiosos" (Oliveras, 2009, p. 188). Con este único nivel local, se simplificarían las decisiones políticas, permitiendo la descentralización municipal para la participación ciudadana en barrios o distritos de las grandes ciudades o en las entidades de población.

Cabe decir que la cooperación municipal bajo la figura de las mancomunidades posee un importante arraigo en Andalucía, y "aunque en determinados casos coinciden con ámbitos territoriales bien definidos, a veces denominados específicamente como comarcas (Campo de Gibraltar, por ejemplo), no puede hablarse de una embrionaria comarcalización del territorio andaluz basada en la división del territorio llevada a cabo por las mancomunidades" (Feria, 2013, p. 20). En Andalucía existen un total de 83 mancomunidades en las que se agrupan 522 municipios $(66,5 \%)$, por lo que la asociación voluntaria de municipios para la gestión conjunta de competencias que les son propias no está lo suficientemente extendida en toda la región (en Jaén solo cuatro municipios están mancomunados, ya que es una provincia en la que abundan los consorcios, promovidos por la diputación). Ahora bien, un buen número de los ayuntamientos, no precisamente los de mayor población (el 69,5\% de los mismos no alcanza los 5.000 hab.), siguen sin pertenecer a ninguna mancomunidad, existiendo un índice significativo de solapamiento entre las distintas mancomunidades, si bien la mayoría de los municipios mancomunados $(63,3 \%)$ pertenecen a una única mancomunidad.

Para Andalucía, como consecuencia del reducido número de pequeños municipios en comparación con otras regiones (3,9\% en el rango de hasta 250 habitantes y 27,9\% hasta 1.000 habitantes), lo más apropiado sería una organización político-administrativa del ámbito supramunicipal (sin acudir a fórmulas coercitivas para la fusión de municipios), mediante el desarrollo normativo de las comarcas, una vez liberada esta figura administrativa del corsé de la uniprovincialidad que condicionó, incluso, propuestas académicas de comarcalización para Andalucía (Cano, 2002); estableciendo así un marco competencial propio que les permitiera aglutinar los servicios supramunicipales que hasta el momento están siendo ejecutados por las diputaciones provinciales y las mancomunidades de municipios, lo que, en ocasiones, supone una duplicación de esfuerzos hacia la consecución de un mismo objetivo.

Sin embargo, la estrategia estatal está lejos de planteamientos que fomenten la agrupación de municipios en entes supramunicipales; así, con la entrada en vigor de la LRSAL (2013), se ve reforzado el papel de las diputaciones provinciales, encomendándoles la coordinación de determinados servicios mínimos en los municipios con población inferior a 20.000 habitantes o la atribución a éstas de nuevas funciones como la prestación de servicios de recaudación tributaria, administración electrónica, contratación centralizada, participación activa en la elaboración y seguimiento en los planes económico-financieros 
o las labores de coordinación y supervisión, en colaboración con las comunidades autónomas, de los procesos de fusión de municipios.

\section{CONCLUSIONES}

En Andalucía, la constitución de nuevos municipios, por segregación de otro ya existente, se ha visto incrementada de forma considerable en la última década, a pesar de la limitación poblacional que impone la LRSAL (mínimo de 5.000 habitantes para poder constituir un nuevo ayuntamiento), encontrando resquicios legales por medio de la culminación de procesos segregacionistas incoados con anterioridad a su entrada en vigor (1 de enero de 2014), en contraposición con los postulados técnicos y, en general, políticos que pretenden una reducción significativa del número de municipios.

Se han comentado las diversas fórmulas que se pueden aplicar para alcanzar la tan ansiada sostenibilidad económica y la eficiencia en la gestión de competencias: reducción del número de municipios (agrupaciones o fusiones), fomento de la cooperación municipal (mancomunidades y consorcios), creación de figuras supramunicipales (comarcas y áreas metropolitanas), e incluso la aparición de un doble nivel local; que deberían fomentarse en función de las características de cada territorio. Sin embargo, cualquier iniciativa legislativa que suponga la reducción del mapa municipal conllevará, con gran probabilidad, el enfrentamiento político y social entre los que la promuevan y las corporaciones locales, por lo que su tramitación debe ser transparente y lo más participativa posible.

Además, es importante alcanzar soluciones específicas a la problemática del minifundismo local, pues cada espacio posee unas características de poblamiento que requiere de soluciones distintas, debiendo tenerse presente en todo momento lo recogido, en relación con la delimitación territorial, en la Carta Europea de la Autonomía Local (1985), que señala que para cualquier modificación de los límites territoriales locales, las colectividades autóctonas afectadas deberán ser consultadas previamente, llegado el caso, por vía de referéndum, allá donde la legislación lo permita, como podría suceder en Andalucía.

\section{REFERENCIAS}

Arenilla, M. (2012). El pequeño municipio: núcleo democrático vs. prestación de servicios. En Fundación Democracia y Gobierno Local (ed.), Elementos para un debate sobre la Reforma Institucional de la Planta Local en el Estado Autonómico (pp. 159-220), España, Fundación Democracia y Gobierno Local. Recuperado de: http://repositorio.gobiernolocal.es/xmlui/bitstream/handle/10873/1328/10_Arenill a_p159_220.pdf? sequence $=1(22 / 05 / 2020)$.

Burgueño, J. (2004). El eterno debate sobre la reforma del mapa municipal: el caso de Cataluña. Revista de geografía, (3), 7-33. Recuperado de: https://www.raco.cat/index.php/RevistaGeografia/article/view/46140

Burgueño, J., y Guerrero, M. (2014). El mapa municipal de España. Una caracterización geográfica. Boletín de la Asociación de Geógrafos Españoles, (64), 11-36. https://doi.org/10.21138/bage.1687 
Calonge, A. (2015). La fusión de municipios, único instrumento de la Ley 27/2013, de 27 de diciembre, de racionalización y sostenibilidad de la Administración Local para la modificación de la planta municipal: una oportunidad perdida. REALA. Nueva época, (9), 47-58. https://doi.org/10.24965/reala.v0iExtra.10222

Cano, G. (2002). Una propuesta de comarcalización para Andalucía. En G. Cano (dir.), Conocer Andalucía: Gran Enciclopedia Andaluza del Siglo XXI, volumen 10 (pp. 11-85), Ediciones Tartessos.

Carbonell, E. (2018). La alteración de términos municipales en la reforma local de 2013: crónica de un fracaso anunciado. REALA. Nueva época, (9), 5-21. https://doi.org/10.24965/reala.v0i9.10513

Carta Europea de Autonomía Local. Estrasburgo, 15 de octubre de 1985. Recuperado de: https://www.boe.es/buscar/act.php?id=BOE-A-1989-4370 (21/05/2020).

Casassas, L., y Clusa, J. (1981). L'organització territorial de Catalunya. Publicacions de la Fundació Jaume Bofill.

Copano, L. (2018). Autonomía Local, Organización Territorial y Segregación Municipal. Revista de Estudios Andaluces, (35), 63-100. http://dx.doi.org/10.12795/rea.2018.i35

Copano, L., y Ventura, J. (2013). La organización del territorio submunicipal en Andalucía. Criterios administrativos para su delimitación. Revista de Estudios Regionales, (98), 155-191. Recuperado de: http://www.revistaestudiosregionales.com/documentos/articulos/pdf-articulo2425.pdf (20/05/2020).

Decreto de 16 de diciembre de 1950 por el que se aprueba el texto articulado de la Ley de Régimen Local de 17 de julio de 1945. Recuperado de: https://www.boe.es/buscar/doc.php?id=BOE-A-1950-13571 (19/50/2020).

Decreto de 17 de mayo de 1952 por el que se aprueba el Reglamento de población y demarcación territorial de las Entidades Locales. Recuperado de: https://www.boe.es/buscar/doc.php?id=BOE-A-1952-6555 (19/50/2020).

Decreto de 24 de junio de 1955 por el que se aprueba el texto articulado y refundido de las Leyes de Bases de Régimen Local, de 17 de julio de 1945 y de 3 de diciembre de 1953. Recuperado de: https://www.boe.es/buscar/doc.php?id=BOE-A-1955$9871(19 / 50 / 2020)$.

Feria, J. Mª (2013). Redes de cooperación local como expresiones de nueva gobernanza. En J. M ${ }^{a}$. Feria (coord.), Mancomunidades, consorcios, áreas metropolitanas y redes de municipios (pp. 13-30), Fundación Pública Andaluza Centro de Estudios Andaluces. Recuperado de: https://www.centrodeestudiosandaluces.es/datos/factoriaideas/IFO16_13.pdf (23/05/2020).

Florido, G. (2003). Poblamiento y hábitat rural: caracterización, evolución y situación actual. En A. López (coord.), Geografía de Andalucía (pp. 329-357). Ariel.

Geografía Infinita (2015). ¿Quién se atreve a cambiar el mapa municipal español? Recuperado de: https://www.geografiainfinita.com/2015/04/quien-se-atreve-acambiar-el-mapa-municipal-espanol/?fbclid=IwAR3fRsPmra4-PJNaX-

U8EnsN4iojcoihmlZ1MjLnbApLtinkhUHvxnNRAXU (04/05/2020). 
Infante, J. (2010). Aproximación al modelo de comarcalización de Aragón. Una reflexión crítica. Boletín de la Asociación de Geógrafos Españoles, (52), 59-80. Recuperado de: http://age.ieg.csic.es/boletin/52/04-INFANTE.pdf (12/05/2020).

Jordana, L. (1967). La previsible alteración de nuestra división territorial. Revista de Estudios de la Administración Local y Autonómica, (155), 641-660. https://doi.org/10.24965/reala.vi155.7598

Ley 27/2013, de 27 de diciembre, de racionalización y sostenibilidad de la Administración Local. Recuperado de: https://www.boe.es/eli/es/1/2013/12/27/27/con (11/05/2020).

Ley 41/1975, de 19 de noviembre, de Bases del Estatuto de Régimen Local. Recuperado de: https://www.boe.es/buscar/doc.php?id=BOE-A-1975-23920 (11/05/2020).

Ley 5/2010, de 11 de junio, de autonomía local de Andalucía. Recuperado de: https://www.boe.es/eli/es-an/1/2010/06/11/5/con (11/05/2020).

Ley 7/1985, de 2 de abril, Reguladora de las Bases del Régimen Local (1985). Recuperado de. https://www.boe.es/buscar/act.php?id=BOE-A-1985-5392 $(11 / 05 / 2020)$.

Ley 7/1993, de 27 de julio, reguladora de la Demarcación Municipal de Andalucía. Recuperado de: https://www.boe.es/eli/es-an/1/1993/07/27/7 (11/05/2020).

Llorente, T. (2014). Reorganización administrativa territorial como vehículo para la racionalización de la estructura de la administración local. Revista Lebret, (6), 369393. https://doi.org/10.15332/rl.v0i6.1462

Llucià, E. (2011). ¿Es necesario modificar el mapa territorial municipal? La solución: áreas básicas administrativas. Cuadernos de Derecho Local, (26), 102-119. Recuperado de: http://hdl.handle.net/10873/1000 (11/05/2020).

Membrado, J. C. (2016). Entes territoriales de escala comarcal en la Administración local española. Documents d'Anàlisi Geogràfica, $62 \quad$ (2), 347-371. http://dx.doi.org/10.5565/rev/dag.300

Oliveras, J. (2009). Reflexions sobre l'organització territorial de Catalunya. Treballs de la Societat Catalana de Geografia, (67-68), 179-198.

Palomar, A. (2015). La supresión-fusión de municipios. Cuadernos de derecho local, (37), 225-265. Recuperado de: https://repositorio.gobiernolocal.es/xmlui/bitstream/handle/10873/1653/Supresion _fusion_municipios_Palomar_Olmeda_p_225_265.pdf?sequence=1\&isAllowed= y $(28 / 05 / 2020)$.

Real Decreto 1690/1986, de 11 de julio, por el que se aprueba el Reglamento de Población y Demarcación Territorial de las Entidades Locales. Recuperado de: https://www.boe.es/eli/es/rd/1986/07/11/1690 (11/05/2020).

Real Decreto 3046/1977, de 6 de octubre, por el que se articula parcialmente la Ley 41/1975, de Bases del Estatuto de Régimen Local, en lo relativo a los funcionarios públicos locales y otros extremos. Recuperado de https://www.boe.es/buscar/doc.php?id=BOE-A-1977-28230 (11/05/2020).

Rodríguez, R. (2005). Territorio y gobierno local en España. Un planteamiento de reestructuración por fusión como realidad necesaria. Civitas. 
Santiago, D. (2012). La reforma del mapa local español a debate: la fusión de Municipios. Istituzioni del federalismo: rivista di studi giuridici e politici, (1), 167-190. Recuperado de: http://www.regione.emiliaromagna.it/affari_ist/Supplemento1_12/Iglesias.pdf (12/05/2020).

Trillas, A. (2010). Suprimir municipios, misión imposible. El País, 28 de julio. Recuperado de: https://elpais.com/diario/2010/07/28/sociedad/1280268001_850215.html (09/05/2020).

Ventura, J. (1991). Tensiones en el poblamiento andaluz y problemas de administración territorial: el caso de Isla Mayor. Revista de Estudios Andaluces, (16), 93-113. https://doi.org/10.12795/rea.1991.i16.06

Ventura, J., y Ayala, J. (1987). Concentración y dispersión: características del poblamiento andaluz. En G. Cano (dir.), Geografía de Andalucía, volumen III, Población, Poblamiento y Ciudades de Andalucía (pp. 207-257). Tartessos. 


\section{EXTENDED ABSTRACT ${ }^{15}$}

The Andalusian municipal map is currently made up of 785 councils, although this political, administrative and territorial reality has experienced a significant boom in segregationist phenomena during the constitutional period. As a result, the number of municipalities has increased: 26 segregations compared to only 2 additions to neighboring municipal terms, especially numerous municipal independences during the last decade, with the creation of 14 new councils, most of them with a legal basis in the Local Autonomy Law of Andalusia (LAULA, 2010), all of that despite the restrictive requirement to obtain municipal independence subject to ratification by the plenary session of the parent council, and the condition of the minimum threshold of 5.000 inhabitants established by the Law of Rationalization and Sustainability of the Local Administration (LRSAL, 2013) for the segregation files initiated as of January 1, 2014. All that in accordance with the technical and, in general political, postulates that, in theory, a significant reduction in the number of municipalities.

The objective of this research has been to deepen the current position of the Junta de Andalucía in relation to the processes of creation and deletion of municipal terms, applying for it, as a methodology, a review of all the regulations on local regime and its repercussions on the Andalusian municipal map. The main motivations to grant or deny municipal segregation have been studied in depth, although it seems quite clear that the Andalusian Community has opted for the use of article 95.1 a) of the LAULA, that is, by means of a plenary agreement of the parent council, discarding section c) of the same article, which refers to the initiation of the procedure by the competent Regional Ministry on local regime, since to date ex officio segregation procedure has not been promoted by this Autonomous Community.

However, this rigorous character has not been established as an insurmountable barrier that has prevented the successful completion of segregation initiatives, and in fact, up to 14 segregation decrees have been published in recent years, 7 of them in October 2018, with population clearly reduced, despite various unfavorable opinions from the Andalusian Advisory Council.

However, future options for municipal segregation are subject to exceeding the minimum population threshold of 5.000 inhabitants, which is a strict requirement, since $85 \%$ (a total of 528) of Andalusian municipalities do not even reach this limit. This implies that of the more than 13.000 existing settlements in Andalusia (counting both population centres and scattered at the toponymical level), only 34 of them would meet the demographic requirement. In addition, it should be borne in mind that none of these settlements has become an Autonomous Local Entity, and that most of the secondary centres are actually coastal urbanizations very close to their municipal capital or to the main population centres of another municipality, lacking identity own, so that, in practice, puts a stop to segregation, despite the fact that in certain populations there is still a strong feeling of differentiated identity.

Regarding mergers, despite the fact that the LRSAL has placed special emphasis on them, establishing some promotion measures in the economic and tax field, it does not seem that, with the new regulation, the voluntary merger of municipalities will be followed by many of them, not even in those cases that are immersed in processes of economic sanitation. In addition, there is no option for one of the merged municipalities to maintain

15 Traducción exclusiva de los autores / Authors' exclusive translation. 
a position of differentiated administrative identity, since they cannot be constituted as EATIM (ELA in Andalusia), but only as a form of decentralized, and not decentralized, organization, such as EATIMES, which we can consider as residual local entities, by not allowing, with the current legislation, the creation of new ones.

However, although the new article 116 bis of the Local Regime Bases Regulatory Law (LRBRL, 1985), advocates a case of merger of a forced or sanctioning nature, by formulating an economic-financial plan that will include, among other issues, a proposal for a merger with an adjoining municipality, within the same province, it is not foreseeable that the Junta de Andalucía will make use of this possibility, since the aforementioned forced mergers are a more than debatable measure in constitutional terms and although there are many proposals from the political sphere to reduce the number of municipalities, a real generalized and consensual political will would be needed.

Furthermore, since the Junta de Andalucía has transferred competences in matters of local regime, there have only been two cases: the incorporation of Almería municipalities of Benínar (1984) and Darrícal (1997), bordering those of Berja and Alcolea respectively, as a consequence of the construction of the Benínar reservoir, and therefore caused by an unforeseen reason.

It is necessary to overcome the opposing positions between those who bet on a significant reduction in the number of primary territorial entities, following the line set by countries in Southern Europe such as Portugal, and those that position themselves by strengthening municipal cooperation or creation of supra-municipal figures. It should be borne in mind that the problem of local minifundism does not have the same territorial affection, so that the organizational-territorial solutions must not be homogeneous either. Thus, within the population threshold of 250 inhabitants, the Autonomous Communities with the highest percentage of municipalities would be Castilla y León (61,9 \%), La Rioja (61,5\%), Aragón (57,6 \%), Castilla-La Mancha $(44,5 \%)$, Navarra $(40,4 \%)$ and Catalonia $(19,3 \%)$.

Therefore, keeping in mind the specificity of each region, a possible solution to local minifundism could be to create a double local level: maintaining the municipalities as a political community and citizen participation that would allow the local identity to be preserved, except in the case that it does not reach the minimum population threshold; while the management and provision of services are carried out within the framework of a supra-municipal territorial space.

It should be said that municipal cooperation under the figure of the communities of municipalities has an important roots in Andalusia, although in certain cases they coincide with well-defined territorial areas, it is still not possible to speak of an embryonic regionalization of Andalusian territory based on the territorial division of the communities of municipalities, since in Andalusia only 522 municipalities $(66,5 \%)$ belong to some of them, so the voluntary association of municipalities for the joint management of their own competencies is not sufficiently widespread throughout the region.

For Andalusia, as a consequence of the low number of small municipalities compared to other regions $(3,9 \%$ in the range of up to 250 inhabitants and $27,9 \%$ up to 1.000 inhabitants), the most appropriate would be the empowerment of political-administrative organizations of supra-municipal scope (without resorting to coercive formulas for the merger of municipalities), through the regulatory development of administrative regions, establishing their own competence framework that would allow them to bring together the supra-municipal services that up to now are being carried out by the provincial council 
and the communities of municipalities, and that, on occasions, involves a duplication of efforts towards the achievement of the same objective.

However, the state strategy is far from approaches that promote the grouping of municipalities in supra-municipal entities. Thus, with the entry into force of the LRSAL (2013), the role of the provincial councils has been strengthened, entrusting them with the coordination of certain minimum services of the municipalities with a population of less than 20.000 inhabitants or the attribution to these provincial entities of new functions in collaboration with the autonomous communities.

In conclusion, to achieve the long-awaited economic sustainability and efficiency in the management of competencies, various formulas can be applied, such as reducing the number of municipalities (groups or mergers), promoting municipal cooperation (communities of municipalities and consortiums), the creation of supra-municipal figures (administrative regions and metropolitan areas), and even the appearance of a double local level. However, any legislative initiative that involves the reduction of the municipal map will, with great probability, entail political-social tensions between those who promote it and local corporations, so its processing must be transparent and as participatory as possible.

In addition, it is important to reach specific solutions to the problem of local minifundism, since each space has characteristics of settlement that require different solutions, and what has been taken into account, in relation to territorial delimitation, must be taken into account in the European Charter of the Local Autonomy (1985), which indicates that for any modification of the local territorial limits, the affected native communities must be consulted beforehand, if necessary, by way of referendum, wherever the law allows it, as it could perfectly well be in the Andalusia case. 


\section{CONTRIBUCIÓN SEGÚN AUTORES}

\begin{tabular}{|c|l|c|c|}
\hline \multicolumn{1}{|c|}{ ITEM } & Luis Copano & Jesús Ventura \\
\hline 1 & Conceptualización & $45 \%$ & $55 \%$ \\
\hline 2 & Tratamiento de los datos & $70 \%$ & $30 \%$ \\
\hline 3 & Análisis formal & $80 \%$ & $20 \%$ \\
\hline 4 & Acceso financiación & $0 \%$ & $0 \%$ \\
\hline 5 & Investigación & $45 \%$ & $55 \%$ \\
\hline 6 & Metodología & $40 \%$ & $60 \%$ \\
\hline 7 & Gestión del proyecto & $40 \%$ & $60 \%$ \\
\hline 8 & Recursos & $50 \%$ & $50 \%$ \\
\hline 9 & Software & $80 \%$ & $20 \%$ \\
\hline 10 & Supervisión & $35 \%$ & $65 \%$ \\
\hline 11 & Validación & $40 \%$ & $60 \%$ \\
\hline 12 & Visualización & $70 \%$ & $30 \%$ \\
\hline 13 & Redacción (borrador) & $60 \%$ & $40 \%$ \\
\hline 14 & Redacción final (revisión y edición) & $60 \%$ & $40 \%$ \\
\hline
\end{tabular}

Para más información, visitar CRediT: https:/casrai.org/credit/ 